status of the doctor and placed responsibility in the right place. No advance was possible until this readjustment had taken place. He was associated with the scheme for the formation of the Advisory Board, consisting of military men and of civil and military medical men, upon a much broader basis than the system which the Board displaced. At this time there was an Army Merlical. School at Netley, where certain things only could be learnt, but there was no place where a man could go in order to brighten up rusty or deficient knowledge, or to learn what was new in medicine or surgery since he qualified. A scheme was then in progress, and money had been voted for the purpose of enlarging Netley, but Sir Alfred Keogh saw at once that such a place ought to be in London, and at his instigation the Netley extension was stopped and the Netley school boldly brought to London. At first it was housed temporarily in the laboratories of the Colleges of Physicians and Surgeons, but he saw that, as the Millbank Military Hospital was being built; the right place for his school would be near to it, and so the Royal Army Medical College was built with all the necessary arrangements for post-graduate teaching and training and for research work, and with facilities for acquiring new knowledge in any branch. Sir Alfred Keogh was also the first Director-General to encourage research among the better men of the R.A.M.C., and it was through his influerice that such men as the late Major Fry and Capt. Ranken, V.C., were encouraged and permitted to undertake research work for the Royal Society, with results sufficient to justify publication in the Proceedings of the Royal Society.

When Sir Alfred Keogh became Deputy-DirectorGeneral there was no special sanitary service in the Army, and the knowledge of sanitation and hygiene, and of all that these words connote, which was possessed by the doctors was of the most elementary kind. He saw that if this were not rectified there would be a terrible and unnecessary loss of life in the next war, and he set himself to draw up a scheme by which a special branch of the Army Medical Service, devoted to sanitary science, should be created. He also insisted that the principles of sanitary science should be taught to the military students as a part of their ordinary course, as well as to the members of the R.A.M.C., and even to the combatant officers; a School of Army Sanitation was founded, and directors of Medical Sanitary Service were provided for the armies in the field, and a sanitary officer was placed on the staff of each command. This scheme had to wait years for its realisation, and it is to the credit of Lord Haldane that it was owing to his initiative and support that it became law. It is the application of science to sanitation which has helped in a very great measure to reduce the incidence of disease in the present war to the remarkable figures which have been published. Bound up with this is the question of watter supply to the troops, and a branch of the Medical Service has had special instruction in the examination and disinfection of water, thus ensuring a safe and wholesome supply. Sir Alfred Keogh also initiated and superintended a long series of experiments on the kind and quantity of food necessary for soldiers, and as the result a system of food-rationing was arrived at which has, with but few modifications, borne the very severe test of the present war. His attitude towards vaccine therapy shows the same scientific perception. In the South African War many accidents happened owing to our incomplete knowledge of the subject, so he appointed a committee of experts, presided over by Sir W. Leishman, who wrote, as the result of the inquiry, the hisNO. 2523 , VOL. IOI] torical paper which has been the foundation of our present effective and safe methods.

In all these ways. Sir Alfred Keogh prepared the way for the extraordinary results which have followed our treatment of typhoid fever and other diseases by vaccines in the present war; and during the war he has also exercised the same vigilant control by attacking two other diseases in the same scientific spirit-namely, tetanus and trench fever. Tetanus is a rare disease in peace-time, but during the war such numbers of cases occurred that he decided to form a committee for the study of this disease, which, as a result of its researches, would be able to advise as to better methods of treatment, and this has been followed with the best results. He has also formed a committee for the study of the problems of trench fever, which has already achieved important results. In both these cases, besides practical results, our scientific knowledge of the disease has been advanced: he has therefore, in all these instances, helped towards making medicine the possibly scientific pursuit which it is always becoming.

In addition, Sir Alfred Keogh had for two and a half years the direction of the work on poison gas and gas attacks, which work has been of no small advantage to us. But it is rather in the greater work of saving life that his devotion will be remembered, and the country can never forget what it owes to him in this respect. To have reduced disease to a minimum, so that men are more healthy in the field than at home; to have organised a medical service sufficient for our enormous Army, scattered all over the world; to have devised and insisted upon methods of sanitation which have borne the strain of most difficult conditions; to have encouraged and insisted upon research, even during the war, into diseases which have become prominent and about which we know little, forms a record which no mere words can appraise. It is not only that he has done these things, but also that he has done them in the face of great opposition, from both the military and the medical side. His power of imagination, however, controlled by the scientific spirit, has enabled him not only to overcome all the difficulties he has had to face, but also to hand over to another a living machine, which he knows will still act with the spirit he has infused into it, and be capable of answering any calls that may be made upon it.

It is not possible here to speak of Sir Alfred Keogh's work at the Imperial College of Science. There is no doubt that the college has caught something of his spirit, for it has given all its energies in every department to the service of its country, as Sir Alfred Keogh
himself did.

His example will live; let us hope that his words, quoted above, may not be forgotten; may they be, as goads and as nails driven deep in." H. G. P.

\section{THE DEPARTMENTAL REPORT ON} SALARIES IN ELEMENTARY SCHOOLS.

$\mathrm{I}$ view of the important changes that are foreshadowed in the sphere of education in the Bill now before Parliament, the question of a due supply of efficient teachers, especially for the elementary schools, assumes an aspect of high importance. We therefore welcome the carefully considered report, just issued, of the Departmental Committee for inquiring into the principles which determine the construction of scales of salary for teachers in elementary schools (Cd. 8939, price $6 d$. net)

The Committee, of which Sir Harry Stephen was chairman, was comprised of representatives of the 
various interests concerned-administrative and educational-and it received, either personally or by memorandum, the evidence of fifty-six witnesses representative of all shades of opinion and conditions of experience, with the result that a report of sixty-three folio pages of high value has been prepared, which will do much to enhance the position of the teacher. "For many years past," the report states, "it has not been possible to secure recruits in numbers adequate to the needs of the schools.". The position will obviously be seriously aggravated should Mr. Fisher's Bill become law, and the children be required to remain at school until fourteen, and continued education be imposed within the usual hours of labour until the age of eighteen is reached. Not only will a much larger number of teachers be required, but also teachers of higher qualifications.

Already there are in the elementary schools 167,8 Io teachers of all grades, of whom 43,500 are men and 124,310 are women. Of this number 109,250 are trained certificated teachers. There is a constant pressure to induce a still larger number of teachers to go through a course of two or more years of college training with the view of securing either a certificate or a degree, which means that the future teacher will be at least twenty-one or twenty-two years of age before remunerative employment begins, and that on a scale not higher than that of an ordinary artisan.

It will be seen from the above figures how large a proportion of the elementary-school teachers are women, and yet it is clear that, at least for the older boy pupils, it is most desirable that their teachers should be men. The question of a more abundant recruitment is of vital moment, and its solution lies not merely in the establishment of a higher scale of salaries and an adequate pension scheme, but also in better prospects for the more able of the teachers, so that not only should headteacherships be open to them, the average salary of which in England and Wales is about r 767 . for men and $126 l$. for women, but also inspectorships and administrative posts with the central and local authorities.

It cannot be expected that men trained side by side in the same university with prospective lawyers, doctors, divines, men of science, and technologists in industry and commerce seeking degrees of equivalent standing will be content with the poor rewards the profešsion of teaching in the elementary schools offers to able men. If the nation desires that its children shall have a prolonged and satisfactory education in well-equipped schools, and also the best possible training at the hands of capable teachers, there is no course open to it but to pay the price for this essential service, and the reward of the nation will be great.

The report, in its interesting analyses and tables, exhibits an astonishing variety of scales of payments and of increments prevailing in the various areas, urban and rural, of England and Wales, but only in few cases can they be said to be liberal or attractive. There needs to be more uniformity than at present exists in the salaries of teachers, and where the produce of a $I d$. rate per child is low, then it would appear desirable that the central authority, in order that the teacher may not suffer, should give the necessary financial assistance. Based upon the minimum initial salary which the President of the Board of Education stated that he had in mind, namely, rool. for men and $9 o l$. for women, the report offers, by way of illustration, five separate scales, according to the varying circumstances of urban and rural areas, for men and women certificated class teachers, ranging from rool. and gol. respectively to $300 l$. and $240 l$., the maximum varying according to the conditions of the area, and for head- teacherships a like set of illustrative scales, rising to $400 l$. in the case of men and to $300 l$. in that of women, the maximum again to be determined by local conditions.

The principles insisted on in the report are that there should be a reasonable initial payment, and a scale of increment leading to a point representing an adequate salary; that this should be receivable as a matter of right, and as part of the contract, by every teacher whose service is not characterised by definite default or wilful neglect; and that, in order that the increment should be so adjusted as to meet the teachers' needs, the value of the teachers' services should be periodically recognised, so that good service may be encouraged. With respect to the payment of women teachers, the report states. that in the opinion of the Committee the scale of salaries adequate for women is inadequate for men; and that in average circumstances the maximum for women should be three-fourths that for men, and finally suggests that the best method of recognising superior merit in teachers is by advancement to positions of greater responsibility and increased emolument, even if it means a departure from the normal scale.

The report is accompanied by a valuable meinorandum, drawn up by its secretaries, giving a retrospect of methods and scales of payment since the Act of 1870 , and a clear account, illustrated by elaborate comparative tables, of the common features of existing scales in various parts of the country.

\section{METEOROLOGY AND EXACT THERMOMETRY.}

IN the Monthly Weather Review for November, 1917, Prof. C. F. Marvin, Chief of the U.S. Weather Bureau, asks for a short word and corresponding symbol for the temperature on the hydrogen- or adjusted mercury-scale of Centigrade degrees measured from $273^{\circ} \mathrm{C}$. below the normal freezing point of water in place of the word absolute. As he rightly points out, the use of the word in that sense is loose scientific language, because, to those who know, it means not quite the same thing as the absolute thermodynamic scale or true Kelvin scale.

Prof. Marvin's own suggestions for a descriptive name are quasi-absolute, approximate absolute, and pseudo-absolute, not one of which is likely to appeal to the general reader as the mot juste. The question is one of practical importance, because our own Meteorological Office uses the approximate absolute scale in many of its publications for expressing temperatures, together with the millibar scale for pressure, notably in its recent issue of data for the whole world with the title of Réseau Mondial. It has discarded the use of the degree sign for temperature and uses a small a immediately after the numeric, thus placing temperature on the same footing as an ordinary physical quantity like mass or length.

The practice of using absolute c.g.s. units for pressure and the approximate absolute scale for temperature dates from 1909 with the regular publication of data of the upper air in the Weekly Weather Report, and afterwards in the Geophysical Journal, the only change being the adeption of the millibar instead of the megadyne per square centimetre in 1914 , a practice against which Prof. McAdie, of Harvard University, has raised protests on the ground that chemists had already, assigned another meaning to the word bar. In the same year the U.S. Weather Bureau commenced the issue of a daily map of the northern hemisphere in the same units. The millibar was adopted in France for the Bulletin International in I9I7.

The history of scientific progress justifies some loose-

NO. 2523 , VOL. IOI] 